\title{
Review \\ Update on the use of aromatase inhibitors in early-stage breast cancer
}

\author{
Georgios Kesisis, Andreas Makris and David Miles
}

Mount Vernon Cancer Centre, Rickmansworth, Northwood, Middlesex, HA6 2RN, UK

Corresponding author: Georgios Kesisis, kesgeo@hotmail.com

Published: 28 October 2009

This article is online at http://breast-cancer-research.com/content/11/5/211

(c) 2009 BioMed Central Ltd
Breast Cancer Research 2009, 11:211 (doi:10.1186/bcr2410)

Of the trials involving newly diagnosed women, there are two main trial structures:

- 5 years of an Al versus 5 years of tamoxifen

- A planned switch (that is, sequence) involving 2 years of tamoxifen followed by 3 years of an Al versus 2 years of an Al followed by 3 years of tamoxifen versus 5 years of tamoxifen.

Of the trials involving women currently taking tamoxifen, there are two main trial structures:

- An unplanned switch from tamoxifen to an Al following 2 to 3 years of tamoxifen versus 5 years of tamoxifen

- An unplanned switch after 5 years of tamoxifen to an $\mathrm{Al}$ or placebo for a further 5 years.

The American Society of Clinical Oncology (ASCO) Technology Assessment of Als states that optimal adjuvant hormonal therapy for a postmenopausal woman with hormone receptor-positive $\mathrm{BC}$ should include an $\mathrm{Al}$ [8]. The National Institute for Health and Clinical Evidence (NICE) has also recommended Als, within their licensed indications, as options for the adjuvant treatment of early-stage $\mathrm{ER}^{+}$invasive $\mathrm{BC}$ in postmenopausal women who are newly diagnosed and those women currently on tamoxifen [9]. However, due to a lack of results from directly comparative trials, neither guideline was able to recommend one particular treatment strategy over another.

Uncertainty remains as to the most appropriate treatment strategy, particularly for newly diagnosed women, as they seek to trade off the cost, toxicities and efficacy of the

$\mathrm{ABCSG}=$ Austrian Breast \& Colorectal Cancer Study Group; Al = aromatase inhibitor; ARNO = Arimidex-Nolvadex; ASCO = American Society of Clinical Oncology; ATAC = Arimidex, Tamoxifen, Alone or in Combination; BC = breast cancer; BIG = Breast International Group; BMD = bone mineral density; $\mathrm{Cl}=$ confidence interval; DFS = disease-free survival; DVT = deep vein thrombosis; ER = oestrogen receptor; HER2 = human epidermal growth factor receptor 2; HR = hazard ratio; $\mathrm{HRQoL}=$ health-related quality of life; IES = Intergroup Exemestane Study; ITA = Italian Tamoxifen Arimidex; ITT = intention to treat; $\mathrm{MI}=$ myocardial infarction; MRI = magnetic resonance imaging; NICE = National Institute for Health and Clinical Evidence; NSABP = National Surgical Adjuvant Breast and Bowel Project; OS = overall survival; PR $=$ progesterone receptor; PTH $=$ parathyroid hormone; RFS = relapse-free survival; $\mathrm{SE}=$ standard error; VTE = venous thromboembolic event. 
treatment options. Recent publications provide conflicting advice on the role of $\mathrm{Al}$ in the treatment of postmenopausal patients with early-stage hormone receptor-positive BC. On one hand, Chlebowski [10] recommends up-front Al for the majority of patients, whereas Seruga and Tannock [11] suggest that tamoxifen remains the endocrine treatment of choice for most patients.

\section{Newly diagnosed postmenopausal women with hormone receptor-positive early breast cancer Trials comparing 5 years of an aromatase inhibitor versus 5 years of tamoxifen \\ The ATAC trial}

The Arimidex, Tamoxifen, Alone or in Combination (ATAC) study, involving 9,366 patients, was the first of these trials to report and remains a 'landmark' trial in the treatment of early BC. The initial report in The Lancet, with a median follow-up of 33.3 months, demonstrated the superiority of anastrozole compared with tamoxifen with 3-year DFS rates of $91.2 \%$ for anastrozole versus $89.3 \%$ for tamoxifen in hormone receptorpositive patients (hazard ratio [HR] 0.78, 95\% confidence interval [Cl] of 0.65 to $0.93, P=0.005$ ) [12]. Results with the combination were not significantly better than tamoxifen alone (HR $1.02,95 \% \mathrm{Cl}$ of 0.87 to $1.21, P=0.8$ ). The combination arm has not been analysed subsequently, and it is unlikely that other trials of combinations of Als and tamoxifen will be undertaken. In the latest update of this trial, with a median follow-up of 100 months, anastrozole significantly increased DFS in the hormone receptor-positive population by $74.2 \%$ versus $70.1 \%$ for tamoxifen (HR $0.85,95 \% \mathrm{Cl} 0.76$ to 0.94 , $P=0.003$ ) [13]. In anastrozole-treated patients, risk of recurrence was reduced by $24 \%$ (HR $0.76,95 \% \mathrm{Cl} 0.67$ to 0.87 , $P=0.0001)$ compared with tamoxifen. Risk of contralateral $\mathrm{BC}$ was significantly reduced in the anastrozole arm by $40 \%$ (HR $0.60,95 \% \mathrm{Cl} 0.42$ to $0.85, P=0.004$ ) compared with tamoxifen. OS was similar with anastrozole and tamoxifen (HR 0.97, 95\% Cl 0.86 to $1.11, P=0.7$ ).

\section{The BIG 1-98 Collaborative Group study}

This four-arm trial compared 5 years of tamoxifen versus 5 years of letrozole, versus 2 years of tamoxifen plus 3 years of letrozole, versus 2 years of letrozole and 3 years of tamoxifen. This key study was designed to evaluate whether a planned sequence of tamoxifen and letrozole (and vice versa) provides benefits compared with 5 years of letrozole. A total of 8,010 women with hormone receptor-positive BC were randomly assigned. In the head-to-head comparison of letrozole versus tamoxifen for 5 years, at a median follow-up of 25.8 months, 351 events were noted in the letrozole arm and 428 with tamoxifen, with estimated 5-year DFS rates of $84.0 \%$ for letrozole and $81.4 \%$ for tamoxifen [14]. The risk of distant recurrence was also significantly reduced (HR $0.73,95 \% \mathrm{Cl}$ of 0.60 to $0.88, P=0.001$ ).

More data from this trial were recently published [15]. This involved 4,922 patients (only those patients who continued in the monotherapy arms following the crossover of the trial) with a median follow-up of 51 months. Three hundred fiftytwo events were recorded in the letrozole arm compared with 418 with tamoxifen, with estimated 5-year DFS rates of $84.0 \%$ versus $81.1 \%$ with tamoxifen ( $\mathrm{HR} 0.82,95 \% \mathrm{Cl}$ of 0.71 to $0.95, P=0.007)$.

The results published in 2005 in favour of letrozole led to the unblinding of the tamoxifen-alone arm, and $25.2 \%$ of the patients selectively switched to letrozole for a median duration of receiving letrozole of 18 months. As a result, the analysis recently reported with 76 months of follow-up was divided as either intention to treat (ITT) or by censoring patients who switched. In this latest update [16], there is a statistically significant difference in DFS (HR 0.88, 95\% Cl 0.78 to 0.99 , $P=0.03)$ for both ITT and censored populations and a trend for OS benefit in the ITT population (HR 0.87, 95\% Cl 0.75 to $1.02, P=0.8)$ which reached significance in the censored population (HR $0.81,95 \% \mathrm{Cl} 0.69$ to 0.94 ).

A meta-analysis of Als versus tamoxifen in the adjuvant setting was presented by Dr Ingle at the recent San Antonio Breast Cancer Symposium [17]. The analysis was divided in two cohorts. The first was a direct comparison of monotherapy strategies and included data from the ATAC and Breast International Group (BIG) 1-98 trials. It included 9,856 patients with 50,000 woman-years of follow-up. At 5 years, Al therapy was associated with an absolute $2.7 \%$ (standard error [SE] $0.7 \%$ ) decrease in $\mathrm{BC}$ recurrence $(10.7 \%$ versus $13.4 \%$, relative decrease 20\% [SE 5\%], $P=0.00004)$. There appeared to be greater proportional decreases in isolated local recurrence $(30 \%$ [SE 10\%], $P=0.003)$ and in contralateral disease (38\% [SE 12\%], $P=0.003)$ than in distant recurrence (12\% [SE 6\%], $P=0.04$ ). There was, however, no significant improvement in BC mortality $(5.5 \%$ versus $6.5 \%$, relative decrease $7 \%$ [SE $7 \%$ ], $P=0.28$ ).

\section{Postmenopausal women with hormone receptor-positive early breast cancer currently receiving adjuvant tamoxifen Sequencing endocrine treatments}

The fundamental difference in the design of the following trials is the time point of random assignment. The switch trials randomly assign patients after 2 to 3 years of adjuvant endocrine treatment, whereas the sequencing trials randomly assign patients from the start of treatment. As a consequence, the former (switch) trial design selects a patient population who have not already relapsed and may therefore have a better prognosis and may potentially have tumours that are more endocrine-responsive.

\section{Switching trials}

The IES trial

In the Intergroup Exemestane Study (IES) trial, 4,742 patients who had received 2 to 3 years of tamoxifen were randomly assigned to receive exemestane or continue tamoxifen to a 
total of 5 years of hormonal therapy. After a median follow-up of 30.6 months, the results favoured exemestane. Of a total of 449 events (local or metastatic recurrence, contralateral BC or death), 183 were in the exemestane group and 266 in the tamoxifen group [18]. The unadjusted HR in the exemestane group was 0.68 (95\% $\mathrm{Cl} 0.56$ to $0.82, P<0.001)$, representing a 32\% reduction in risk and an absolute benefit in terms of DFS of $4.7 \%$ compared with tamoxifen 3 years following random assignment. DFS rates 3 years after random assignment (following 2 to 3 years of tamoxifen treatment) were $91.5 \%$ in the exemestane group versus $86.8 \%$ in the tamoxifen group. There was no significant difference in OS, with 93 deaths in the exemestane group and 106 in the tamoxifen group. A more recent analysis was published, with a median follow-up of 55.7 months [19]. There were 354 events in patients switched to exemestane versus 455 in the tamoxifen group (ITT population, HR $0.76,95 \% \mathrm{Cl} 0.66$ to 0.88 , $P=0.0001)$. In patients with hormone receptor-positive or unknown disease, 339 events were noted in the exemestane group compared with 438 in those continuing tamoxifen (HR $0.75,95 \% \mathrm{Cl} 0.65$ to $0.87, P=0.0001)$. These latest IES data estimated absolute differences in 5 -year DFS of $3.4 \%$ in the ITT population and 3.5\% in the hormone receptor-positive and unknown group compared with tamoxifen.

This analysis also showed an improvement in OS in the group treated with exemestane versus tamoxifen. In the ITT population, the result failed to reach conventional levels of statistical significance, with 222 deaths versus 261 deaths in the exemestane and tamoxifen arms, respectively (HR 0.85, $95 \% \mathrm{Cl} 0.71$ to $1.02, P=0.08)$. Considering the hormone receptor-positive and unknown group, the difference was barely statistically significant, with 210 deaths in the exemestane arm versus 251 with tamoxifen (HR 0.83, 95\% Cl 0.69 to $1.00, P=0.05$ ).

\section{The ARNO 95 trial}

Analysis of the Arimidex-Nolvadex (ARNO) 95 trial at a median of 30.1 months, published in 2007, demonstrated estimated DFS rates at 3 years of $93.5 \%$ for anastrozole versus $89.3 \%$ for tamoxifen, with an absolute difference of $4.2 \%$ [20]. An OS benefit was seen in patients who switched to anastrozole versus those who continued to receive tamoxifen (HR $0.53,95 \% \mathrm{Cl} 0.28$ to $0.99, P=0.045$ ).

\section{Meta-analysis of the ABCSG 8, the ARNO 95 and the ITA} trials

In the unplanned switching meta-analysis, including the Austrian Breast \& Colorectal Cancer Study Group (ABCSG) 8, ARNO 95 and Italian Tamoxifen Arimidex (ITA) trials, involving 4,006 patients at a median follow-up of 30 months, there were significantly fewer recurrences (92 events [4.6\%] versus 159 events [8.0\%]) and significantly fewer deaths (66 [3.3\%] versus 90 [4.5\%]) in the group switched to anastrozole versus those remaining on tamoxifen [21]. A 29\% reduction in risk of death in the anastrozole arm ( $\mathrm{HR} 0.71$,
$95 \% \mathrm{Cl}$ of 0.52 to $0.98, P=0.04$ ) versus the tamoxifen arm was seen. The anastrozole arm also demonstrated a $45 \%$ improvement in event-free survival (HR 0.55, 95\% Cl of 0.42 to $0.71, P<0.0001)$ and a $39 \%$ improvement in distant recurrence-free survival ( $\mathrm{HR} 0.61,95 \% \mathrm{Cl}$ of 0.45 to 0.83 , $P=0.0015)$.

\section{Sequencing trials}

The ABSCG Trial 8

The ABSCG Trial 8 explored the tamoxifen-Al sequencing strategy in postmenopausal women with hormone-responsive early BC. The ABSCG Trial 8 compared 5 years of tamoxifen versus 2 years of tamoxifen followed by 3 years of anastrozole [22]. A recent update of this trial at a median of 72 months of follow-up showed that sequencing tamoxifen to anastrozole significantly improved relapse-free survival (RFS) in the ITT population by $21 \%(\mathrm{HR} \quad 0.79,95 \% \mathrm{Cl} 0.65$ to 0.95 , $P=0.038)$. Patients treated with sequential endocrine treatment showed significantly improved OS, with a $23 \%$ reduction in the number of deaths ( $\mathrm{HR} 0.77,95 \% \mathrm{Cl} 0.61$ to $0.97, P=0.025)$.

\section{The BIG 1-98 trial}

Results of the sequencing arms of the trial as described previously were recently presented [15], with a median follow-up of 71 months. Two pairwise comparisons were presented: letrozole versus sequencing 2 years of letrozole followed by 3 years of tamoxifen (Let $x 2 \rightarrow$ Tam $x 3$ ) or sequencing 2 years of tamoxifen followed by 3 years of letrozole (Tam x2 $\rightarrow$ Let $x 3$ ). Although no statistically significant differences in DFS were demonstrated (5-year DFS rates of $87.9 \%$ for Let, $87.6 \%$ for Let $x 2 \rightarrow$ Tam $x 3$ and $86.2 \%$ for Tam $\times 2 \rightarrow$ Let $\mathrm{x} 3$ ), subset analysis revealed an increased risk of recurrence in the first 2 years of treatment in the Tam x2 $\rightarrow$ Let $x 3$ group, especially for the node-positive population. There was no apparent benefit of the letrozolealone versus the [Let $\times 2 \rightarrow$ Tam $x 3$ ] strategy at this stage of follow-up.

\section{The TEAM trial}

The Tamoxifen Exemestane Adjuvant Multinational (TEAM) trial was originally designed as a monotherapy comparison of 5 years of examestane versus tamoxifen. However, the results of the IES trial led to the amendment of the protocol and all patients on tamoxifen switched to examestane. The median time patients on the tamoxifen arm took tamoxifen was 2.75 years. At a median of 2.75 years of follow-up [23], the trial failed to reach its primary endpoint, DFS (HR 0.89, 95\% Cl 0.77 to $1.03, P=0.12$ ), but was associated with improvements in RFS (HR 0.85, 95\% Cl 0.72 to $1.00, P=0.05$ ) and time to distant metastases (HR $0.81,95 \% \mathrm{Cl} 0.67$ to 0.98 , $P<0.03)$.

Meta-analysis of the switch strategy

A meta-analysis reviewed the switch strategy [17] using data from the GABG (German Adjuvant Breast Study Group)/ 
ARNO, IES/BIG 2-97, ITA and ABCSG 8 trials. The analysis included 9,015 patients with 33,000 woman-years of followup. At 6 years from treatment divergence (that is, 8 to 9 years from allocation to endocrine treatment), Al therapy was associated with an absolute 3.5\% (SE 1.1\%) decrease in BC recurrence $(12.6 \%$ versus $16.1 \%$, relative decrease $29 \%$ [SE $6 \%], P<0.00001)$. There appeared to be greater proportional reductions in isolated local recurrence (40\% [SE 13\%], $P=0.002)$ and in contralateral disease (35\% [SE 16\%], $P=0.03)$ than in distant recurrence (24\% [SE 7\%], $P=0.001$ ). Als yielded an absolute 1.6\% (SE 0.8\%) decrease in BC mortality $(6.3 \%$ versus $8.0 \%$, relative decrease $22 \%$ [SE $9 \%], P=0.02)$. The benefit was irrespective of progesterone receptor (PR) status, age, grade and lymph node status. Furthermore, there was no evidence of increase in overall mortality or non-BC deaths with the use of the $\mathrm{Al}$, causing no concern about safety issues.

Trial comparing 5 years of 'extended' treatment with an aromatase inhibitor versus 5 years of placebo following 5 years of adjuvant treatment with tamoxifen

The MA-17 trial

Due to the early termination of the National Cancer Institute of Canada MA-17 (MA-17) trial, its aims will never be answered. The trial involved 5,187 patients who had already received tamoxifen for 5 years and then were randomly assigned to a further 5 years' therapy with either letrozole or placebo. At a median follow-up of 2.4 years, the independent data and safety monitoring committee recommended termination of the trial as a significant difference in favour of letrozole was seen. The estimated 4-year DFS rates were $93 \%$ and $87 \%$ for letrozole and placebo, respectively $(P<0.001)$ [24]. More recent analysis of the MA-17 trial now indicates a survival benefit for extended adjuvant therapy with letrozole in lymph node-positive patients (HR 0.61, $P=0.04$ ) [25].

In the MA-17 trial, patients were randomly assigned within 3 months of stopping tamoxifen. The effect of 'delayed' extended adjuvant therapy with letrozole has been evaluated in those women who, after unblinding of the trial, opted for an unplanned switch from placebo to letrozole. Compared with the hormone receptor-positive women who chose not to do so and despite having worse prognostic features, those who switched had significantly improved DFS (HR $0.31,95 \% \mathrm{Cl}$ 0.18 to $0.55, P<0.0001$ ) [26].

\section{Comparison of toxicity of Als versus tamoxifen in newly diagnosed patients and those patients currently taking tamoxifen switched to an Al \\ Venous thromboembolic events}

Trials of Als versus tamoxifen show a lower risk of venous thromboembolic events (VTEs) with Als. The exact mechanism that potentiates thrombotic events is unclear but possibly involves, among other mechanisms, tamoxifeninduced decrease in antithrombin III and protein C levels
$[27,28]$. Previous trials of tamoxifen versus placebo have shown a significant increase in the risk of VTEs, which may be related to its partial agonist oestrogenic actions. In the National Surgical Adjuvant Breast and Bowel Project (NSABP) P1 trial, the risk ratios for stroke (1.59), pulmonary embolism (3.01) and deep vein thrombosis (DVT) (1.60) were all raised with tamoxifen treatment compared with placebo [29].

After 68 months of follow-up in the ATAC trial, the incidence of any thromboembolic event was lower with anastrozole compared with tamoxifen (2.1\% versus $3.5 \%, P=0.0006)$ and also for VTEs (3\% versus $5 \%, P=0.0004$ ) [30]. Similarly, in the BIG 1-98 trial, letrozole was associated with fewer thromboembolic events compared with tamoxifen $(1.5 \%$ versus $3.5 \%, P<0.001)$. The switching trials have also shown a reduction in VTEs: The IES trial showed incidences of VTEs of $1.0 \%$ for exemestane and $1.9 \%$ for tamoxifen $(P=0.003)$. The combined analysis of ABCSG 8 and ARNO 95 showed 21 VTEs with tamoxifen and only 5 with anastrozole [31]. In the MA-17 trial, VTEs were rare and not significantly different from the placebo. From the above, it is clear that patients with a previous VTE should receive an Al rather than tamoxifen, irrespectively of recurrence risk.

\section{Gynaecological side effects}

The oestrogen agonist activity of tamoxifen on endometrium can be associated with vaginal bleeding and discharge, menstrual irregularities and endometrial changes (hyperplasia, polyps, endometriosis and uterine fibroids), and an increased incidence of endometrial cancer is recognised. In the NSABP P1 prevention study, there was a 2.5 -fold increase in endometrial cancer with tamoxifen treatment [29]. Most studies involving Als in the adjuvant setting report a reduced incidence of vaginal bleeding, with a reduced need for interventions such as hysterectomy $(5.1 \%$ versus $1.3 \%)$ in the 68-month follow-up ATAC data [12] and endometrial biopsy $(7.2 \%$ versus $1.9 \%)$ being reported in the 25.8 -month follow-up BIG 1-98 data [14]. Given the absence of agonist activity of the Als, the incidence of vaginal discharge is usually reported as being less with this class of agents. In the two available Al quality-of-life studies carried out, decreased libido, vaginal dryness and dyspareunia were reported more frequently with anastrozole and exemestane than tamoxifen [32,33].

Hot flashes, either de novo or exacerbation of pre-existing symptoms, are a recognised feature of endocrine therapies, reported in up to $46 \%$ of patients [34]. They are attributed to the sudden decrease in circulating oestrogen levels, and due to their abrupt onset, they are more bothersome than the symptoms developed during natural menopause. Hot flashes are reported with slightly less frequency in the two studies in newly diagnosed women: $36 \%$ for anastrozole versus $41 \%$ for tamoxifen after 68 months of follow-up [12] and 34\% for letrozole versus $38 \%$ for tamoxifen after 25.8 months of follow-up [14]. In studies exploring unplanned switching 
strategies, the reported incidence of hot flashes is broadly similar to that of other studies [18,31]. Unsurprisingly, in the MA-17 study of extended adjuvant therapy, use of letrozole led to a higher frequency of hot flashes compared with placebo (47\% versus 41\%, respectively) [24]. Interestingly, in one study, women who reported hot flashes at baseline were less likely to develop recurrent $\mathrm{BC}$ than those who did not report hot flashes (12.9\% versus $21 \%, P=0.01$ ) [35].

\section{Bone mineral density}

Trials of Als versus tamoxifen in postmenopausal women have shown an increased risk of fractures with the use of all Als $[12,14,18]$. Comparisons between Als and tamoxifen are complicated by the fact that the effect of tamoxifen on bone mineral density (BMD) is not neutral but agonistic [36]. Previous trials of tamoxifen compared with placebo in postmenopausal women have shown an increase in BMD from tamoxifen use and a 19\% reduction (nonsignificant) in the incidence of fractures [29].

In the ATAC trial at 68 months, the incidences of fractures were $11 \%$ with anastrozole versus $7.7 \%$ with tamoxifen. The 5 -year bone subprotocol of the ATAC trial showed that the loss of BMD from baseline was an average of $6.1 \%$ in the lumbar spine and $7.2 \%$ in the hip with anastrozole compared with a $2.8 \%$ gain in the lumbar spine and $0.7 \%$ gain in the hip with tamoxifen $(P<0.0001)$ [37]. However, no patient with normal bone at baseline became osteoporotic after 5 years of treatment; to develop osteoporosis, a woman would need to lose $15 \%$ to $20 \%$ of normal peak bone mass. In the BIG 1-98 study, fractures were significantly more frequent in the letrozole group than in the tamoxifen group at 25.8 months (5.7\% versus $4 \%, P<0.001)$ [13].

In the IES trial at 55.7 months of follow-up, rates of osteoporosis (of any grade) were $7.0 \%$ with exemestane and $4.9 \%$ with tamoxifen $(P=0.003)$ [18]. In the MA-17 trial at 2.4 years, rates of osteoporosis (of any grade) were $5.8 \%$ with letrozole and $4.5 \%$ with placebo $(P=0.07)$ [24].

Although claims of superiority have been made for particular Als with respect to bone loss [38], the LEAP (Letrozole, Exemestane, and Anastrozole Pharmacodynamics) trial involving 90 patients at 24 weeks of treatment showed that the steroidal and nonsteroidal Als appear to have similar effects on bone biochemical measurements and presumably bone turnover. All three licensed Als result in increases in bone turnover. With the exception of parathyroid hormone (PTH), in which there is a greater decrease in PTH with exemestane than with anastrozole $(P=0.04)$, there were no statistically significant differences between the Als [39].

At present, it is not clear to what extent the difference in bone density seen between Als and tamoxifen is due to their direct effect on bone or to the absence of the bone preservation effect of tamoxifen. It is reassuring that the relative incidence of fractures with anastrozole has not increased over time in the ATAC trial and appears to stabilise after 2 years $[12,30,40,41]$. Recent trials have provided evidence that osteopenia/osteoporosis, either present at the start of therapy with Als or developing during treatment, can be prevented with the use of bisphosphonates [42-44]. Guidance on the management of bone loss induced by the use of Als has recently been published (Figure 1).

\section{Arthralgia}

Als have been associated with a broad range of musculoskeletal adverse events (in addition to the effects on bone health described in the preceding paragraph) that have been loosely categorised under the term of Al-related arthralgias. In the trials of adjuvant Al therapy such as ATAC, IES, BIG 1-98 and $\mathrm{MA}-17$, bone and joint symptoms were categorised in a variety of ways, and estimates for the incidence of musculoskeletal problems in these trials range from 5\% to $36 \%$ [45]. However, this may be an underestimate in view of the inconsistency of reporting these symptoms. Crew and colleagues [46] reported a cross-sectional survey of 200 consecutive women receiving adjuvant $\mathrm{Al}$ therapy, with a higher prevalence of these symptoms. Ninety-four (47\%) reported having Al-related joint pains, and 88 (44\%) reported joint stiffness. Patients who had received taxanes were four times more likely to report symptoms. The pathophysiology of Alrelated arthralgias is not well understood, but it is thought to be related to oestrogen deprivation. Magnetic resonance imaging (MRI) studies have suggested that tenosynovial changes are seen on MRI with Als but not with tamoxifen, and these correlate with a significant decrease in hand grip strength [47].

\section{Cardiac side effects}

The cardiovascular consequences of tamoxifen remain the subject of much debate. Tamoxifen has been shown to reduce lipid levels [48], coronary plaques and C-reactive protein and modulate nitric oxide production [49]. However, the clinical consequences of these changes are uncertain and trials of tamoxifen versus placebo in the preventive setting have not indicated differences in cardiac events [50].

At 28 months of follow-up, the BIG 1-98 trial reported a significant excess of cardiac (2.1\% versus $1.1 \%, P=0.0003)$ grade 3 to 5 events for the letrozole-containing arm [51]. However, at a median follow-up of 51 months, no significant differences in cardiovascular events in the two arms of the study were seen [15].

In the ATAC trial, no statistically significant differences in cardiac events were reported. Ischaemic cardiovascular disease occurred in $4.1 \%$ of patients receiving anastrozole versus $3.4 \%$ in the tamoxifen arm, and deaths due to ischaemic heart disease occurred in 49 and 46 patients, respectively. The ABCSG 8, ARNO 95 and ITA trials have not reported an excess of cardiovascular disease or 


\section{Algorithm 2: Postmenopausal adjuvant treatment with aromatase inhibitors}

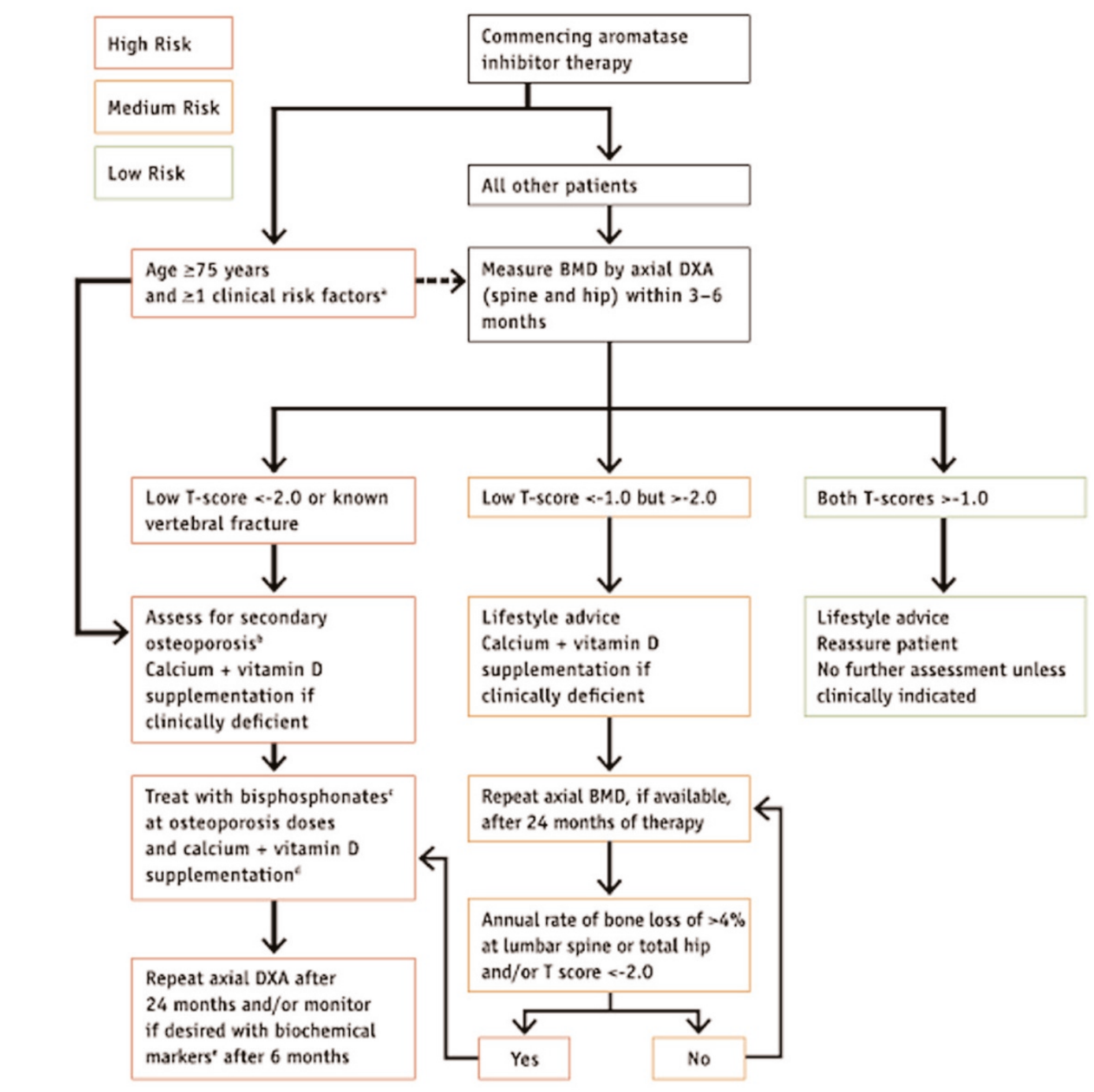

a Previous low-trauma fracture after age 50, parental history of hip fracture, c Alendronate $70 \mathrm{mg}$ per week, risecronate 35 ng per week, ibundronate

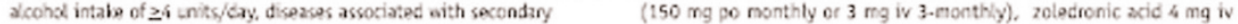

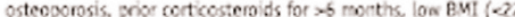

b ESR, IBC, bone and liver function (calcion, phosphate, alkaline phosphatase, albumin, AST / GT), serum creatinine, endortysial antibodies, serum thyoid stimulating hormone

Guidelines on the management of postmenopausal women treated with aromatase inhibitors. AST, aspartate aminotransferase; BMD, bone mineral density; BMI, body mass index; DXA, dual-energy x-ray absorptiometry; ESR, erythrocyte sedimentation rate; FBC, full blood count; GT, glutamine transpeptidase. Adapted with permission from [81].

myocardial infarctions (Mls) with anastrozole compared with tamoxifen [52].

In the most recent update of the IES trial [19], deaths from cardiac events were similar in exemestane and tamoxifen groups (22.1\% versus $20.9 \%, P=0.34)$. Additionally, there were no statistically significant differences in Mls (1.3 versus $0.8, P=0.08)$, angina $(7.1 \%$ versus $6.5 \%, P=0.44)$ or cerebrovascular accidents (2.5\% versus $2.4 \%, P=0.89$ ) observed. In the extended adjuvant setting, letrozole was not associated with more cardiovascular events than placebo at a median follow-up of 2.4 years [24].

At present, it is not clear whether the early concerns with cardiac morbidity in the BIG 1-98 trial are specific to letrozole or are a class effect of Als. Inconsistency in cardiac event 
Table 1

\begin{tabular}{|c|c|c|c|c|c|c|c|}
\hline Trial & Al versus tamoxifen & Strategy & Follow-up, months & $\begin{array}{c}\text { DFS } \\
\text { HR }\end{array}$ & $\begin{array}{c}\text { DFS } \\
P \text { value }\end{array}$ & $\begin{array}{l}\text { OS } \\
\text { HR }\end{array}$ & $\begin{array}{c}\text { OS } \\
P \text { value }\end{array}$ \\
\hline ATAC & Anastrozole & Up-front & 100 & 0.85 & 0.003 & 0.97 & 0.7 \\
\hline BIG & Letrozole & Up-front & 76 & 0.88 & 0.03 & 0.87 & 0.8 \\
\hline BIG & Letrozole-Tamoxifen & Sequencing & 71 & 0.96 & NS & & NS \\
\hline BIG & Tamoxifen-Letrozole & Sequencing & 71 & 1.05 & NS & & NS \\
\hline TEAM & Examestane & Up-front & 33 & 0.89 & 0.12 & & NS \\
\hline IES & Examestane & Sequencing & 55.7 & 0.76 & 0.0001 & & NS \\
\hline ARNO & Anastrozole & Sequencing & 30 & 0.66 & 0.049 & 0.53 & 0.045 \\
\hline MA-17 & Letrozole & Extended & 30 & 0.58 & 0.001 & & NS \\
\hline ABCSG 6a & Anastrozole & Extended & 62 & 0.62 & 0.031 & & NS \\
\hline
\end{tabular}

ABCSG, Austrian Breast \& Colorectal Cancer Study Group; Al, aromatase inhibitor; ARNO, Arimidex-Nolvadex; ATAC, Arimidex, Tamoxifen, Alone or in Combination; BIG, Breast International Group; DFS, disease-free survival; HR, hazard ratio; IES, Intergroup Exemestane Study; NS, not significant; OS, overall survival; TEAM, Tamoxifen Exemestane Adjuvant Multinational.

reporting in the major Al trials makes cross-trial interpretation difficult. Further follow-up of existing trials is needed, and head-to-head trials of Als will help to answer these important questions. Current data suggest that Als are not associated with an excess risk of cardiovascular events.

\section{Quality-of-life evaluations}

The first published results from a longitudinal follow-up of the impact of 5 years of adjuvant Al therapy on health-related quality of life (HRQoL) involved anastrozole and showed that the efficacy and tolerability benefits of anastrozole compared with tamoxifen over the full 5-year recommended adjuvant treatment period are not at the expense of HRQoL [53]. The switch from tamoxifen to exemestane did not influence endocrine symptoms present after 2 to 3 years of tamoxifen, nor did the switch lead to significant reports of new symptoms. Results indicate that the clinical benefits of exemestane over tamoxifen are achieved without significant detrimental effect on quality of life [33]. Data from the MA-17 trial indicate no overall adverse effect of letrozole in quality of life but small, though significant, worse outcomes in body pain and vasomotor symptoms [54].

\section{Discussion}

Three different third-generation Als have been compared with tamoxifen (and in the case of letrozole versus placebo in the extended adjuvant setting) in the context of early-stage BC (Table 1). The largest studies have examined the Als initiated at different disease time points with different patient populations involving different reporting methodologies with respect to efficacy and toxicity. Direct comparison of these $\mathrm{Al}$ trials is thereby problematic.

While follow-up of these studies is relatively short compared with the wealth of data on tamoxifen, the studies demonstrate that Als significantly improve DFS, event-free survival and distant recurrence compared with tamoxifen. More recent data now show an OS benefit in patients switched to anastrozole and exemestane compared with continuation of tamoxifen $[18,20,21]$. Also, OS has been shown to improve in node-positive patients treated with letrozole in the extended adjuvant trial after 5 years of tamoxifen versus placebo [25].

In speculating what the longer-term benefits of Als might be, it is important to recognise that a carryover effect of adjuvant therapies is well recognised with differences in RFS and OS increasing beyond the treatment period. For example, the difference in mortality attributable to tamoxifen at 5 years was only $3.6 \%$ compared with $9.2 \%$ at 15 years, and this for a comparison of active treatment versus none [1]. Similarly, it is interesting to consider an early Swedish trial comparing use of tamoxifen for 2 years versus 5 years [55]. No benefits of the more prolonged treatment were noted before 5 years following random assignment. With the benefit of more prolonged follow-up and the Oxford overviews, 5 years of tamoxifen has, until recently at least, been regarded as the standard of care in early-stage BC. In adjuvant endocrine therapy, prolonged follow-up to truly evaluate long-term benefits is clearly required.

Als have also demonstrated significant improvements in tolerability compared with tamoxifen. Whilst these benefits should be balanced with the increased risk of fracture and arthralgia posed by Als, patients considered to be low risk in terms of recurrence could benefit from the altered toxicity profile of Als compared with tamoxifen. Overall, efficacy benefits have been established without an apparent detrimental effect on quality of life in the anastrozole and exemestane studies [32,33]. 
The ASCO guidelines and the NICE technology appraisal on the use of Als concur that optimal adjuvant hormonal therapy for a postmenopausal woman with receptor-positive BC includes an $\mathrm{Al}$, either as initial therapy or after treatment with tamoxifen $[8,9]$. However, the practical questions remain: when to initiate an $\mathrm{Al}$ and in which patients.

\section{Tamoxifen metabolism}

Tamoxifen has relatively low affinity for its target, the ER, but its metabolites 4-OH-tamoxifen and endoxifen ( $\mathrm{N}$-desmethyl4-hydroxytamoxifen) are 10 to 100 times more potent. In the liver, tamoxifen is converted to $\mathrm{N}$-desmethyl-tamoxifen by CYP3A4/5 and subsequently to endoxifen by CYP2D6. An alternate route of endoxifen production is mediated by CYP2D6, converting tamoxifen to 4-hydroxy-tamoxifen, which is further metabolized to endoxifen via CYP3A4/5. Serum levels of endoxifen are 5 to 10 times higher than that of 4$\mathrm{OH}$-tamoxifen and 100 times more than that of tamoxifen, and therefore endoxifen is considered the main active metabolite [56-58]. The enzyme CYP2D6 (as well as CYP3A4/5) is a member of the cytochrome P450 system and is involved in the oxidation of a wide range of substrates. Besides being involved in tamoxifen metabolism, it metabolizes codeine to morphine. About $7 \%$ of Caucasians carry null alleles, which are homozygous polymorphisms that encode for an inactive allele [59].

Interest in tamoxifen metabolites started with a report by Goetz and colleagues [60] which correlated response to tamoxifen with CYP2D6 polymorphisms. Until now, the evidence has been mixed, with the majority of the studies suggesting that patients with defective tamoxifen metabolism (as a consequence of either genetic polymorphisms or the concomitant use of drugs that inhibit CYP2D6) have an inferior clinical outcome. However, there are also clinical studies indicating the opposite, or no detrimental effect [61]. Another two clinical studies presented in ASCO 2009 reported contradictory results $[62,63]$. In 2006, the US Food and Drug Administration issued a label warning in the tamoxifen package, and several companies now offer genotyping tests to assess CYP2D6 status. At present, one cannot draw definite conclusions regarding the appropriateness of fullscale genotype testing, although most practitioners would avoid the concomitant use of strong pharmacologic inhibitors of CYP2D6 with tamoxifen and some may even provocatively consider that the small increase in efficacy with the modern Als over tamoxifen would be lost [64] if poor metabolizers were excluded from the clinical trials.

\section{Biomarkers to guide the use of adjuvant endocrine therapy}

Patients with hormone-responsive disease represent a spectrum with differing degrees of clinical benefit derived from adjuvant endocrine treatments. The level of expression of ERs correlates with the degree of response to endocrine therapies [65] but does not differ between tamoxifen and Als.
Similarly for PRs [66], the benefit correlates with the level of expression. Initially, it was suggested that $\mathrm{ER}^{+} \mathrm{PR}^{-}$tumours gain even more benefit with anastrozole compared with tamoxifen than the rest of the hormone-responsive tumours [67]; however, subsequent studies failed to confirm this [66]. Preclinical studies have suggested that overexpression of human epidermal growth factor receptor 2 (HER2) in hormone receptor-positive tumours is associated with endogenous resistance to tamoxifen [68]. Retrospective clinical data indicate that HER2 overexpression in advanced BC is associated with relative resistance to treatment with tamoxifen [69] and greater benefits from the use of an $\mathrm{Al}$ [70]. Similar results have been shown in the neoadjuvant setting [71], but not in the adjuvant setting [66,72]. Finally, the presence of high levels of Ki-67 indicates aggressive disease and can be used as a predictive marker for choosing an $\mathrm{Al}$ over tamoxifen in the adjuvant setting [73], with significant benefits in DFS (HR [Let:Tam] $0.53,95 \% \mathrm{Cl} 0.39$ to 0.72 ). Current data indicate that biomarkers may define a group with some resistance to endocrine therapy but do not justify the use of these biomarkers in routine clinical practice in selecting treatment with Als over tamoxifen.

\section{Newly diagnosed patients}

For newly diagnosed patients, those at high risk of early recurrence (including patients with nodal involvement and/or high-grade tumours, $\mathrm{PR}^{+}$tumours or $\mathrm{HER} 2^{+}$tumours) are more likely to benefit from the introduction of an Al up front. Some patients considered to be low risk in terms of recurrence may also be considered for an up-front $\mathrm{Al}$ on the basis of the improved tolerability that Als offer versus tamoxifen.

Initial reports from the ATAC trial generated the hypothesis of an increased benefit in the PR- tumours [67], but subsequent reports refuted this hypothesis [66]. To date, there are no data to support elective use of an $\mathrm{Al}$ in a particular endocrineresponsive subset. High expression of HER2 has been suggested to confer resistance to tamoxifen [74], and there are data from the neoadjuvant setting that letrozole is more effective than tamoxifen in women with HER2 ${ }^{+}$tumours [75]. However, there are no robust data from the major adjuvant trials to establish this practice. Despite this, women overexpressing HER2 are at higher risk of early relapse and could be candidates for an Al on this basis. Prospectively sequencing newly diagnosed patients to 2 years of tamoxifen, followed by 3 years of an Al, may be appealing with respect to toxicity, with adverse effects of each agent lessened with reduced exposure.

\section{Patients currently on tamoxifen}

For these patients, the unplanned switch approach appears appealing if reduction in risk of relapse is considered, and compared with 'up-front' comparisons, this approach appears to be associated with a survival benefit. Patients randomly assigned in these switching studies, however, were those who had not recurred already and probably represent a more 
Table 2

Licensed indications of different aromatase inhibitors

\begin{tabular}{lll}
\hline Treatment & Newly diagnosed patients & Patients currently treated with tamoxifen \\
\hline Anastrozole & Primary adjuvant & Unplanned switch following 2 to 3 years of tamoxifen \\
Exemestane & Not applicable & Unplanned switch following 2 to 3 years of tamoxifen \\
Letrozole & Primary adjuvant & Unplanned switch following 5 years of tamoxifen (extended adjuvant) \\
\hline
\end{tabular}

endocrine therapy-sensitive group. For patients who have received 2 to 3 years of tamoxifen, completion of 5 years of endocrine therapy that includes an Al should be considered.

While the optimal duration of endocrine therapy was generally regarded as being about 5 years, the results of the extended adjuvant therapy trial (MA-17) challenge this view. Patients with node-positive disease who have received 5 years of tamoxifen benefit from the introduction of an $\mathrm{Al}$ [24]. The optimal duration remains unclear following the early discontinuation of the study as mandated by the trial design. Recent follow-up data of the MA-17 trial suggest that benefits of an Al are seen versus placebo in patients even following its late introduction [26].

The results of trials of extended tamoxifen have been inconsistent. Reports from earlier trials $[76,77]$ indicated that no additional advantage was obtained with extended tamoxifen therapy and actually reported a trend toward inferior survival. Only a smaller trial [78] suggested a possible benefit from increasing the length of adjuvant tamoxifen treatment. Two newer trials are trying the resolve the discrepancy. In the first, ATLAS (adjuvant tamoxifen, longer against shorter), the longer duration of tamoxifen therapy was associated with a $12 \%$ relative reduction in the risk for $B C$ recurrence compared with 5 years of treatment alone $(\mathrm{HR}=0.88, P=0.05)$ [79]. In the aTTom (adjuvant Tamoxifen-To offer more?) trial, which again compared 5 versus 10 years of adjuvant tamoxifen, there was a nonstatistically significant trend in favour of the longer treatment [80]. Apart from a doubling of the incidence of endometrial tumours, there were no major safety issues raised. In terms of which Al to use, until head-to-head Al trial data comparing efficacy and tolerability are provided, Als should be prescribed within their licensed indications as outlined below (Table 2).

\section{Is there a role for tamoxifen alone?}

For women at low risk of relapse $\left(\mathrm{ER}^{+}, \mathrm{PR}^{+}\right.$, grade $\mathrm{I} / \mathrm{II}$, nodenegative), the benefit of Als in terms of DFS is likely to be small. None of the trials has reported the benefit for low-risk patients in absolute terms. Given the wealth of data in terms of long-term toxicity with tamoxifen, its use may be considered appropriate for such patients. However, even for these patients, Als may be appropriate if patients have contraindications for tamoxifen (for example, DVT/pulmonary embolism) or may be intolerant to the side effects of tamoxifen (for example, hot flashes and night sweats).

\section{Competing interests}

The authors declare that they have no competing interests.

\section{References}

1. Early Breast Cancer Trialists' Collaborative Group (EBCTCG): Effects of chemotherapy and hormonal therapy for early breast cancer on recurrence and 15-year survival: an overview of the randomised trials. Lancet 2005, 365:1687-1717.

2. Bonneterre J, Thürlimann B, Robertson JF, Krzakowski M, Mauriac L, Koralewski P, Vergote I, Webster A, Steinberg M, von Euler M: Anastrozole versus tamoxifen as first-line therapy for advanced breast cancer in 668 postmenopausal women: results of the tamoxifen or Arimidex randomized group efficacy and tolerability study. J Clin Oncol 2000, 18:3748-3757.

3. Nabholtz JM, Buzdar A, Pollak M, Harwin W, Burton G, Mangalik A, Steinberg M, Webster A, von Euler M: Anastrozole is superior to tamoxifen as first-line therapy for advanced breast cancer in postmenopausal women: results of a North American multicentre randomized trial. J Clin Oncol 2000, 18:37583767.

4. Bonneterre J, Buzdar A, Nabholtz JM, Robertson JF, Thürlimann B, von Euler M, Sahmoud T, Webster A, Steinberg M; Arimidex Writing Committee; Investigators Committee Members: Anastrozole is superior to tamoxifen as first-line therapy in hormone receptor positive advanced breast carcinoma: results of two randomized trials designed for combined analysis. Cancer 2001, 92:2247-2258.

5. Mouridsen H, Gershanovich M, Sun Y, Perez-Carrion R, Boni C, Monnier A, Apffelstaedt J, Smith R, Sleeboom HP, Jaenicke F, Pluzanska A, Dank M, Becquart D, Bapsy PP, Salminen E, Snyder R, Chaudri-Ross H, Lang R, Wyld P, Bhatnagar A: Phase III Study of letrozole versus tamoxifen as first-line therapy of advanced breast cancer in postmenopausal women: analysis of survival and update of efficacy from the International Letrozole Breast Cancer Group. J Clin Oncol 2003, 21:2101-2109.

6. Johannessen DC, Engan T, Di Salle E, Zurlo MG, Paolini J, Ornati G, Piscitelli G, Kvinnsland S, Lonning PE: Endocrine and clinical effects of exemestane (PNU 155971), a novel steroidal aromatase inhibitor, in postmenopausal breast cancer patients: a phase I study. Clin Cancer Res 1997, 3:1101-1108.

7. di Salle E, Ornati G, Giudici D, Lassus M, Evans TR, Coombes RC: Exemestane (FCE 24304), a new steroidal aromatase inhibitor. J Steroid Biochem Mol Biol 1992, 43:137-143.

8. Winer EP, Hudis C, Burstein HJ, Wolff AC, Pritchard KI, Ingle JN, Chlebowski RT, Gelber R, Edge SB, Gralow J, Cobleigh MA, Mamounas EP, Goldstein LJ, Whelan TJ, Powles TJ, Bryant J, Perkins C, Perotti J, Braun S, Langer AS, Browman GP, Somerfield MR: American Society of Clinical Oncology technology assessment on the use of aromatase inhibitors as adjuvant therapy for postmenopausal women with hormone receptorpositive breast cancer: status report 2004. J Clin Oncol 2005, 23:619-629.

9. NICE Final Appraisal Determination - Hormonal therapies for the adjuvant treatment of early oestrogen-receptor-positive breast cancer, August 2006 [http://www.nice.org.uk/nicemedia/ pdf/breast_cancer_hormonal_FAD.pdf]. 
10. Chlebowski RT: Optimizing aromatase inhibitor integration into initial treatment strategies in postmenopausal women with hormone-receptor-positive early breast cancer. Breast Cancer Res Treat 2008, 112:25-34.

11. Seruga B, Tannock IF: Up -front use of aromatase inhibitors as adjuvant therapy for breast cancer: the emperor has no clothes. J Clin Oncol 2009, 27:840-842.

12. Baum M, Budzar AU, Cuzick J, Forbes J, Houghton JH, Klijn JG, Sahmoud T; ATAC Trialists' Group: Anastrozole alone or in combination with tamoxifen versus tamoxifen alone for adjuvant treatment of postmenopausal women with early breast cancer: first results of the ATAC randomised trial. Lancet 2002, 359:2131-2139.

13. Arimidex, Tamoxifen, Alone or in Combination (ATAC) Trialists' Group, Forbes JF, Cuzick J, Buzdar A, Howell A, Tobias JS, Baum $\mathrm{M}$ : Effect of anastrozole and tamoxifen as adjuvant treatment for early-stage breast cancer: 100-month analysis of the ATAC trial. Lancet Onco/ 2008, 9:45-53.

14. Breast International Group (BIG) 1-98 Collaborative Group, Thürlimann B, Keshaviah A, Coates AS, Mouridsen H, Mauriac L, Forbes JF, Paridaens R, Castiglione-Gertsch M, Gelber RD, Rabaglio M, Smith I, Wardley A, Price KN, Goldhirsch A: A comparison of letrozole and tamoxifen in postmenopausal women with early breast cancer. N Engl J Med 2005, 353: 2747-2757.

15. Coates AS, Keshaviah A, Thürlimann B, Mouridsen H, Mauriac L, Forbes JF, Paridaens R, Castiglione-Gertsch M, Gelber RD, Colleoni M, Láng I, Del Mastro L, Smith I, Chirgwin J, Nogaret JM, Pienkowski T, Wardley A, Jakobsen EH, Price KN, Goldhirsch A: Five years of letrozole compared with tamoxifen as initial adjuvant therapy for postmenopausal women with endocrineresponsive early breast cancer: update of study BIG 1-98. J Clin Oncol 2007, 25:486-492.

16. Mouridsen HT, Giobbie-Hurder A, Mauriac L, Paridaens R, Colleoni M, Thuerlimann B, Forbes JF, Gelber RD, Wardley A, Smith I, Price KN, Coates A, Goldhirsch A, BIG I-98 Collaborative and the International Breast Cancer Study Group: BIG 1-98: a randomized double-blind phase III study evaluating letrozole and tamoxifen given in sequence as adjuvant endocrine therapy for postmenopausal women with receptor-positive breast cancer [abstract 13]. Paper presented at: 31st Annual San Antonio Breast Cancer Symposium; 10-14 December 2008; San Antonio, TX [http://www.abstracts2view.com/sabcs/view. php?nu = SABCS08L 553\&terms =].

17. Ingle JN, Dowsett M, Cuzick J, Davies C: Aromatase inhibitors versus tamoxifen as adjuvant therapy for postmenopausal women with estrogen receptor positive breast cancer: metaanalyses of randomized trials of monotherapy and switching strategies. Paper presented at: 31st Annual San Antonio Breast Cancer Symposium; 10-14 December 2008; San Antonio, TX [http://www.abstracts2view.com/sabcs/view.php?nu = SABCS08L 465\&terms $=$ ].

18. Coombes RC, Hall E, Gibson LJ, Paridaens R, Jassem J, Delozier T, Jones SE, Alvarez I, Bertelli G, Ortmann O, Coates AS, Bajetta E, Dodwell D, Coleman RE, Fallowfield LJ, Mickiewicz E, Andersen J, Lønning PE, Cocconi G, Stewart A, Stuart N, Snowdon CF, Carpentieri M, Massimini G, Bliss JM, van de Velde C; Intergroup Exemestane Study: A randomized trial of examestane after two to three years of tamoxifen therapy in postmenopausal women with primary breast cancer. N Engl J Med 2004, 350: 1081-1092.

19. Coombes RC, Kilburn LS, Snowdon CF, Paridaens R, Coleman RE, Jones SE, Jassem J, Van de Velde CJ, Delozier T, Alvarez I, Del Mastro L, Ortmann O, Diedrich K, Coates AS, Bajetta E, Holmberg SB, Dodwell D, Mickiewicz E, Andersen J, Lønning PE, Cocconi G, Forbes J, Castiglione M, Stuart N, Stewart A, Fallowfield LJ, Bertelli G, Hall E, Bogle RG, Carpentieri M, Colajori E, et al.: Survival and safety of exemestane versus tamoxifen after 2-3 years' tamoxifen treatment (Intergroup Exemestane Study): a randomized controlled trial. Lancet 2007, 369:559570.

20. Kaufmann M, Jonat W, Hilfrich J, Eidtmann H, Gademann G, Zuna I, von Minckwitz G: Improved overall survival in postmenopausal women with early breast cancer after anastrozole initiated after treatment with tamoxifen compared with continued tamoxifen: the ARNO 95 Study. J Clin Oncol 2007, 25:2664-2670.
21. Jonat W, Gnant M, Boccardo F, Kaufmann M, Rubagotti A, Zuna I, Greenwood M, Jakesz R: Effectiveness of switching from adjuvant tamoxifen to anastrozole in postmenopausal women with hormone-sensitive early-stage breast cancer: a metaanalysis. Lancet Oncol 2006, 7:991-996.

22. Jakesz R, Gnant M, Griel R, Tausch C, Samonigg H, Kwasny W, Kubista E, Stierer M, Luschin G, Rüecklinger E, Mittlböck M: Tamoxifen and anastrozole as a sequencing strategy in postmenopausal women with hormone-responsive early breast cancer: updated data from the Austrian breast and colorectal cancer study group trial 8. Paper presented at: 31st Annual San Antonio Breast Cancer Symposium; 10-14 December 2008; San Antonio, TX [http://www.abstracts2view.com/sabcs/view.php?nu= SABCS08L 759\&terms $=$ ].

23. Jones SE, Seynaeve C, Hasenburg A, Rae D, Vannetzel J-M, Paridaens R, Markopoulos C, Hozumi Y, Putter H, Hille E, Kieback D, Asmar L, Smeets J, Urbanski R, Bartlett JMS, van de Velde CJH: Results of the first planned analysis of the TEAM (tamoxifen exemestane adjuvant multinational) prospective randomized phase III trial in hormone sensitive postmenopausal early breast cancer [abstract 15]. Paper presented at: 31st Annual San Antonio Breast Cancer Symposium; 10-14 December 2008; San Antonio, TX [http://www.abstracts2view.com/sabcs/view. php?nu = SABCS08L_55\&terms =].

24. Goss PE, Ingle JN, Martino S, Robert NJ, Muss HB, Piccart MJ, Castiglione M, Tu D, Shepherd LE, Pritchard KI, Livingston RB, Davidson NE, Norton L, Perez EA, Abrams JS, Therasse P, Palmer MJ, Pater JL: A randomized trial of letrozole in postmenopausal women after five years of tamoxifen therapy for early-stage breast cancer. N Engl J Med 2003, 349:17931802.

25. Goss PE, Ingle JN, Martino S, Robert NJ, Muss HB, Piccart MJ, Castiglione M, Tu D, Shepherd LE, Pritchard KI, Livingston RB, Davidson NE, Norton L, Perez EA, Abrams JS, Cameron DA, Palmer MJ, Pater JL: Randomised trial of letrozole following tamoxifen as extended adjuvant therapy in receptor-positive breast cancer: updated findings from NCIC CTG MA17. J Nat Cancer Inst 2005, 97:1262-1271.

26. Goss PE, Ingle JN, Palmer MJ, Shepherd LE: Updated analysis of NCIC MA17 (letrozole versus placebo to letrozole versus placebo) post unblinding [abstract 16]. Breast Cancer Res Treat 2005, 94:S1.

27. Pemberton KD, Melissari E, Kakkar VV: The influence of tamoxifen in vivo on the main natural anticoagulants and fibrinolysis. Blood Coagul Fibrinolysis 1993, 4:935 942.

28. Love RR, Surawicz TS, Williams EC: Antithrombin III level, fibrinogen level, and platelet count changes with adjuvant tamoxifen therapy. Arch Intern Med 1992, 152:317-320.

29. Fisher B, Costantino JP, Wickerham DL, Redmond CK, Kavanah M, Cronin WM, Vogel V, Robidoux A, Dimitrov N, Atkins J, Daly M, Wieand S, Tan-Chiu E, Ford L, Wolmark N: Tamoxifen for prevention of breast cancer: report of the National Surgical Adjuvant Breast and Bowel Project P-1 study. J Natl Cancer Inst 1998, 90:1371-1388.

30. Arimidex, Tamoxifen, Alone or in Combination Trialists' Group, Buzdar A, Howell A, Cuzick J, Wale C, Distler W, Hoctin-Boes G, Houghton J, Locker GY, Nabholtz JM: Comprehensive sideeffect profile of anastrozole and tamoxifen as adjuvant treatment for early-stage breast cancer: long-term safety analysis of the ATAC trial. Lancet Oncol 2006, 7:633-643.

31. Jakesz R, Jonat W, Gnant M, Mittlboeck M, Greil R, Tausch C, Hilfrich J, Kwasny W, Menzel C, Samonigg H, Seifert M, Gademann G, Kaufmann M, Wolfgang J; ABCSG and the GABG: Switching of postmenopausal women with endocrine-responsive early breast cancer to anastrozole after 2 years' adjuvant tamoxifen: combined results of ABCSG trial 8 and ARNO 95 trial. Lancet 2005, 366:455-462.

32. Cella D, Fallowfield L, Barker P, Cuzick J, Locker G, Howell A; ATAC Trialists' Group: Quality of life of postmenopausal women in the ATAC ('Arimidex', Tamoxifen, Alone or in Combination) trial after completion of 5 years' adjuvant treatment for early breast cancer. Breast Cancer Res Treat 2006, 100: 273-284.

33. Fallowfield LJ, Bliss JM, Porter LS, Price MH, Snowdon CF, Jones $\mathrm{SE}$, Coombes RC, Hall E: Quality of life in the intergroup exemestane study: a randomized trial of exemestane versus continued tamoxifen after 2 to 3 years of tamoxifen in post- 
menopausal women with primary breast cancer. J Clin Oncol 2006, 24:910-917.

34. Leining MG, Gelber S, Rosenberg R, Przypyszny M, Winer EP, Partridge AH: Menopausal symptoms in young breast cancer survivors. Ann Oncol 2006, 17:1777-1782.

35. Mortimer JE, Flatt SW, Parker BA, Gold EB, Wasserman L, Natarajan L, Pierce JP; WHEL Study Group: Tamoxifen, hot flashes and recurrence in breast cancer. Breast Cancer Res Treat 2008 108:421-426.

36. Love RR, Mazess RB, Barden HS, Epstein S, Newcomb PA, Jordan VC, Carbone PP, DeMets DL: Effects of tamoxifen on bone mineral density in postmenopausal women with breast cancer. N Engl J Med 1992, 326:852-856.

37. Coleman RE, on behalf of the ATAC Trialists' Group: Effect of anastrozole on bone mineral density: 5-year results from the Arimidex, Tamoxifen, Alone or in Combination (ATAC) trial. 2006 ASCO Annual Meeting Proceedings Part I. J Clin Oncol 2006, 24 (June 20 Suppl):511

38. Lønning PE, Geisler J, Krag LE, Erikstein B, Bremnes Y, Hagen Al, Schlichting E, Lien EA, Ofjord ES, Paolini J, Polli A, Massimini G: Effects of exemestane administered for 2 years versus placebo on bone mineral density, bone biomarkers, and plasma lipids in patients with surgically resected early breast cancer. J Clin Oncol 2005, 23:5126-5137.

39. McCloskey EV, Hannon RA, Lakner G, Fraser WD, Clack G, Miyamoto A, Finkelman RD, Eastell R: Effects of third generation aromatase inhibitors on bone health and other safety parameters: results of an open, randomised, multi-centre study of letrozole, exemestane and anastrozole in healthy postmenopausal women. Eur J Cancer 2007, 43:2523-2531.

40. Howell A, Cuzick J, Baum M, Buzdar A, Dowsett M, Forbes JF, Hoctin-Boes G, Houghton J, Locker GY, Tobias JS; ATAC Trialists' Group: Results of the ATAC (Arimidex, Tamoxifen, Alone or in Combination) trial after completion of 5 years' adjuvant treatment for breast cancer. Lancet 2005, 365:60-62.

41. Baum M, Buzdar A, Cuzick J, Forbes J, Houghton J, Howell A, Sahmoud T; ATAC (Arimidex, Tamoxifen Alone or in Combination) Trialists' Group: Anastrozole alone or in combination with tamoxifen versus tamoxifen alone for adjuvant treatment of postmenopausal women with early-stage breast cancer: results of the ATAC (Arimidex, Tamoxifen Alone or in Combination) trial efficacy and safety update analyses. Cancer 2003, 98:1802-1810

42. Brufsky A, Harker WG, Beck JT, Carroll R, Tan-Chiu E, Seidler C, Hohneker J, Lacerna L, Petrone S, Perez EA: Zoledronic acid inhibits adjuvant letrozole-induced bone loss in postmenopausal women with early breast cancer. J Clin Oncol 2007, 25:829-836.

43. Gnant MF, Mlineritsch B, Luschin-Ebengreuth G, Grampp S, Kaessmann $H$, Schmid M, Menzel C, Piswanger-Soelkner JC Galid A, Mittlboeck M, Hausmaninger H, Jakesz R; Austrian Breast and Colorectal Cancer Study Group: Zoledronic acid prevents cancer treatment-induced bone loss in premenopausal women receiving adjuvant endocrine therapy for hormone-responsive breast cancer: a report from the Austrian Breast and Colorectal Cancer Study Group. J Clin Oncol 2007, 25:820-828.

44. Bundred NJ, Campbell ID, Davidson N, DeBoer RH, Eidtmann $\mathrm{H}$, Monnier A, Neven P, von Minckwitz G, Miller JC, Schenk NL, Coleman RE: Effective inhibition of aromatase inhibitor-associated bone loss by zoledronic acid in postmenopausal women with early breast cancer receiving adjuvant letrozole: ZO-FAST study results. Cancer 2008, 112:1001-1010.

45. Burstein HJ, Winer EP: Aromatase inhibitors and arthralgias: a new frontier in symptom management for breast cancer survivors. J Clin Oncol 2007, 25:3797-3799.

46. Crew KD, Greenlee H, Capodice J, Raptis G, Brafman L, Fuentes D, Sierra A, Hershman DL: Prevalence of joint symptoms in postmenopausal women taking aromatase inhibitors for early-stage breast cancer. J Clin Oncol 2007, 25:3877-3883.

47. Morales L, Pans S, Verschueren K, Van Calster B, Paridaens R, Westhovens R, Timmerman D, De Smet L, Vergote I, Christiaens MR, Neven P: Prospective study to assess short-term intraarticular and tenosynovial changes in the aromatase inhibitor-associated arthralgia syndrome. J Clin Oncol 2008, 26:3147-3152

48. Herrington DM, Klein KP: Effects of SERMs on important indi- cators of cardiovascular health: lipoproteins, hemostatic factors, and endothelial function. Womens Health Issues 2001, 11:95-102.

49. Bradbury BD, Lash TL, Kaye JA, Jick SS: Tamoxifen-treated breast carcinoma patients and the risk of acute myocardial infarction and newly-diagnosed angina. Cancer 2005, 103: 1114-1121.

50. McDonald CC, Alexander FE, Whyte BW, Forrest AP, Stewart $\mathrm{HJ}$ : Cardiac and vascular morbidity in women receiving adjuvant tamoxifen for breast cancer in a randomised trial. $B M J$ 1995, 311:977-980.

51. Nabholtz J-M, Gligorov J: Comparison of cardiovascular safety profiles of aromatase inhibitors. Eur J Cancer Supp/ 2005, 3: 96.

52. Jonat W, Gnant M, Boccardo F Kaufmann M, Rubagotti A, Jakesz R: Switching from adjuvant tamoxifen to anastrozole in postmenopausal women with hormone-responsive early breast cancer: a meta-analysis of the ARNO 95 trial, ABCSG Trial 8 and the ITA trial [abstract 18]. Breast Cancer Res Treat 2005, 94:S1.

53. Fallowfield L, Cella D, Cuzick J, Francis S, Locker G, Howell A: Quality of life of postmenopausal women in the Arimidex, Tamoxifen, Alone or in Combination (ATAC) Adjuvant Breast Cancer Trial. J Clin Oncol 2004, 22:4261-4271.

54. Whelan TJ, Goss PE, Ingle JN, Pater JL, Tu D, Pritchard K, Liu S, Shepherd LE, Palmer M, Robert NJ, Martino S, Muss HB: Assessment of quality of life in MA.17: a randomized, placebo-controlled trial of letrozole after 5 years of tamoxifen in postmenopausal women. J Clin Oncol 2005, 23:6931-6940.

55. Swedish Breast Cancer Cooperative Group: Randomized trial of two versus five years of adjuvant tamoxifen for postmenopausal early stage breast cancer. I Natl Cancer Inst 1996, 21:1543-1549.

56. Garber K: Tamoxifen pharmacogenetics moves closer to reality. J Natl Cancer Inst 2005, 97:412-413.

57. Jin $Y$, Desta $Z$, Stearns $V$, Ward $B$, Ho H, Lee KH, Skaar $T$, Storniolo AM, Li L, Araba A, Blanchard R, Nguyen A, Ullmer L, Hayden J, Lemler S, Weinshilboum RM, Rae JM, Hayes DF, Flockhart DA: CYP2D6 genotype, antidepressant use, and tamoxifen metabolism during adjuvant breast cancer treatment. $J$ Natl Cancer Inst 2005, 97:30-39.

58. Stearns V, Johnson MD, Rae JM, Morocho A, Novielli A, Bhargava P, Hayes DF, Desta Z, Flockhart DA: Active tamoxifen metabolite plasma concentrations after coadministration of tamoxifen and the selective serotonin reuptake inhibitor paroxetine. J Natl Cancer Inst 2003, 95:1758-1764.

59. Ingelman-Sundberg M: Genetic polymorphisms of cytochrome P450 2d6 (CYP2D6): clinical consequences, evolutionary aspects and functional diversity. Pharmacogenomics $J$ 2005, 5: 6-13.

60. Goetz MP, Rae JM, Suman VJ, Safgren SL, Ames MM, Visscher DW, Reynolds C, Couch FJ, Lingle WL, Flockhart DA, Desta Z, Perez EA, Ingle JN: Pharmacogenetics of tamoxifen biotransformation is associated with clinical outcomes of efficacy and hot flashes. J Clin Oncol 2005, 20:9312-9318.

61. Hoskins JM, Carey LA, McLeod HL: CYP2D6 and tamoxifen: DNA matters in breast cancer. Nat Rev Cancer 2009, 9:576586.

62. Aubert RE, Stanek EJ, Yao J, Teagarden JR, Subar M, Epstein RS, Skaar TC, Desta Z, Flockhart DA: Risk of breast cancer recurrence in women initiating tamoxifen with CYP2D6 inhibitors. $J$ Clin Oncol 2009, 27:18s. http://meeting.ascopubs.org/cgi/ content/abstract/27/18S/CRA508

63. Dezentje V, Van Blijderveen NJ, Gelderblom H: Concomitant CYP2D 6 inhibitor use and tamoxifen adherence in early-stage breast cancer: a pharmacoepidemiologic study. J Clin Oncol 2009, 27:18s

64. Punglia RS, Burstein HJ, Winer EP, Weeks JC: Pharmacogenomic variation of CYP2D6 and the choice of optimal adjuvant endocrine therapy for postmenopausal breast cancer: a modeling analysis. J Natl Cancer Inst 2008 100:642-648.

65. Smith IE, Dowsett M, Ebbs SR, Dixon JM, Skene A, Blohmer JU, Ashley SE, Francis S, Boeddinghaus I, Walsh G; IMPACT Trialists Group: Neoadjuvant treatment of postmenopausal breast cancer with anastrozole, tamoxifen, or both in combination: the Immediate Preoperative Anastrozole, Tamoxifen, or Combined with Tamoxifen (IMPACT) multicenter double-blind ran- 
domized trial. J Clin Oncol 2005, 23:5108-5116.

66. Dowsett M, Allred C, Knox J, Quinn E, Salter J, Wale C, Cuzick J, Houghton J, Williams N, Mallon E, Bishop H, Ellis I, Larsimont D, Sasano H, Carder P, Cussac AL, Knox F, Speirs V, Forbes J, Buzdar A: Relationship between quantitative estrogen receptor and progesterone receptor expression and human epidermal growth factor receptor 2 (HER2) status with recurrence in the Arimidex, Tamoxifen, Alone or in Combination Trial. $J$ Clin Oncol 2008, 26:1059-1065.

67. Dowsett M, Cuzick J, Wale C, Howell T, Houghton J, Baum M: Retrospective analysis of time to recurrence in the ATAC trial according to hormone receptor status: an hypothesis-generating study. J Clin Oncol 2005, 23:7512-7517.

68. Benz CC, Scott GK, Sarup JC, Johnson RM, Tripathy D, Coronado E, Shepard HM, Osborne CK: Estrogen-dependent, tamoxifenresistant tumorigenic growth of MCF-7 cells transfected with HER2/neu. Breast Cancer Res Treat 1992, 24:85-95.

69. Houston SJ, Plunkett TA, Barnes DM, Smith P, Rubens RD, Miles DW: Overexpression of c-erbB2 is an independent marker of resistance to endocrine therapy in advanced breast cancer. $\mathrm{Br}$ J Cancer 1999, 79:1220-1226.

70. Lipton A, Ali SM, Leitzel K, Demers L, Harvey HA, Chaudri-Ross HA, Brady C, Wyld P, Carney W: Serum HER-2/neu and response to the aromatase inhibitor letrozole versus tamoxifen. J Clin Oncol 2003, 21:1967-1972.

71. Ellis MJ, Tao Y, Young O, White S, Proia AD, Murray J, Renshaw L, Faratian D, Thomas J, Dowsett M, Krause A, Evans DB, Miller WR, Dixon JM: Estrogen-independent proliferation is present in estrogen-receptor HER2-positive primary breast cancer after neoadjuvant letrozole. J Clin Oncol 2006, 24:3019-3025.

72. Rasmussen BB, Regan MM, Lykkesfeldt AE, Dell'Orto P, Del Curto B, Henriksen KL, Mastropasqua MG, Price KN, Méry E, Lacroix-Triki M, Braye S, Altermatt HJ, Gelber RD, CastiglioneGertsch M, Goldhirsch A, Gusterson BA, Thürlimann B, Coates AS, Viale G; BIG 1-98 Collaborative and International Breast Cancer Study Groups: BIG 1-98 Collaborative and International Breast Cancer Study Groups. Adjuvant letrozole versus tamoxifen according to centrally-assessed ERBB2 status for postmenopausal women with endocrine-responsive early breast cancer: supplementary results from the BIG 1-98 randomised trial. Lancet Oncol 2008, 9:23-28.

73. Viale G, Giobbie-Hurder A, Regan MM, Coates AS, Mastropasqua MG, Dell'Orto P, Maiorano E, MacGrogan G, Braye SG, Ohlschlegel C, Neven P, Orosz Z, Olszewski WP, Knox F, Thürlimann B, Price KN, Castiglione-Gertsch M, Gelber RD, Gusterson BA, Goldhirsch A; Breast International Group Trial 198: Prognostic and predictive value of centrally reviewed Ki67 labeling index in postmenopausal women with endocrine-responsive breast cancer: results from Breast International Group Trial 1-98 comparing adjuvant tamoxifen with letrozole. J Clin Oncol 2008, 26:5569-5575.

74. Dowsett M, Houghton J, Iden C, Salter J, Farndon J, A'Hern R, Sainsbury R, Baum M: Benefit from adjuvant tamoxifen therapy in primary breast cancer patients according oestrogen receptor, progesterone receptor, EGF receptor and HER2 status. Ann Oncol 2006, 17:818-826.

75. Ellis MJ, Coop A, Singh B, Tao Y, Llombart-Cussac A, Jänicke F, Mauriac L, Quebe-Fehling E, Chaudri-Ross HA, Evans DB, Miller WR: Letrozole is more effective neoadjuvant endocrine therapy than tamoxifen for erbB-1- and/or erbB-2-positive, estrogen receptor-positive primary breast cancer: evidence from a phase III randomized trial. $J$ Clin Oncol 2001, 19:38083816.

76. Fisher B, Dignam J, Bryant J, Wolmark N: Five versus more than five years of tamoxifen for node-negative breast cancer: updated findings. J Nat/ Cancer Inst 2001, 93:684-690.

77. Stewart JH, Prescott RJ, Forrest AP: Scottish adjuvant tamoxifen trial: a randomized study updated to 15 years. J Natl Cancer Inst 2001, 93:456-462.

78. Tormey DC, Gray R, Falkson HC: Postchemotherapy adjuvant tamoxifen therapy beyond five years in patients with lymph node-positive breast cancer. J Natl Cancer Inst 1996, 88:18281833.

79. Peto R, Davies C, on Behalf of the ATLAS Collaboration: ATLAS (adjuvant tamoxifen, longer against shorter): international randomized trial of 10 versus 5 years of adjuvant tamoxifen among $\mathbf{1 1 5 0 0}$ women - preliminary results. Breast Cancer
Res Treat 2007, 106 (Suppl 1):http://www.abstracts2view.com/ sabcs07/view.php?nu=SABCS07L 1167\&terms $=$.

80. Gray G, Rea DW, Handley K, Marshall A, Pritchard MG, Perry P, Earl HM, Poole CJ, Salman A, Lee M, and aTTom Collaborators: aTTom (adjuvant Tamoxifen-To offer more?): randomized trial of 10 versus 5 years of adjuvant tamoxifen among 6,934 women with estrogen receptor-positive $\left(\mathrm{ER}^{+}\right)$or $\mathrm{ER}$ untested breast cancer-Preliminary results. J Clin Onco/ 2008, 26:http:// meeting.ascopubs.org/cgi/content/abstract/26/15 suppl/513.

81. Reid DM, Doughty J, Eastell R, Heys SD, Howell A, McCloskey EV, Powles T, Selby P, Coleman RE: Guidance for the management of breast cancer treatment-induced bone loss: a consensus position statement from a UK Expert Group. Cancer Treat Rev 2008, 34 (Suppl 1):S3-18. 